\title{
Research on Mechanical \& Tribological Properties of Natural Fiber Composites
}

\author{
Sk. Ahmad, M.v.j.t.Arun, B.Vimala Kumari, K. Shirley, Ch. Swetha
}

\begin{abstract}
The composite materials play an vital role and all the researchers are attracted towards this research areas and the composite material give an outcome of very enriched material properties which will change our future and avoid so many disadvantages that are facing now here we are discussing about a composite material that is made of resign and hardener by mixing in the proportion of 90:10 percentages that is we add $90 \%$ of the resign to the $10 \%$ of hardener along with the filler material and horn powder.

Here we are interested in checking the material properties that are obtained during our experiment and see how they are differ from the previous ones like they are avoiding toxicity of the material or not and the strength both tensile and compressive and see how much the hardness is increased along with these we also do wear resistance test on the pin on disc experiment setup and obtain their results.
\end{abstract}

Keywords : Nanotubes, Nano-materials, Composite materials, Epoxy resins.

\section{INTRODUCTION}

Composite material is a material made from several materials with more consideration of various physical or chemical properties that, when combined, produce a material with characteristics different from different parts. The composites for various components for manufacturing, construction and transportation within the industry have been specified by industrial designers and engineers. The FRP composites systems being used in installations in the world in order to strengthen or unproved reinforced concrete or masonry structures which are ranging from buildings, parking garages to transportation structures such as bridge columns and decks. In the $20^{\text {th }}$ centary nano technology is used in commercial products. In carbon nano tubes the composites play a vital role. Where as bulk carbon nano tubes

Revised Manuscript Received on December 30, 2019.

* Correspondence Author

Shaik.Ahmad*, Wellfare institute of science Technology and Management(WISTM), Department of mechanical Engineering, Vishakhapatnam, Andhra Pradesh ,India.

M.v.j.t.Arun Wellfare institute of science Technology and Management(WISTM), Department of mechanical Engineering, Vishakhapatnam, Andhra Pradesh ,India.

B.Vimala Kumari,*, Wellfare institute of science Technology and Management(WISTM), Department of mechanical Engineering, Vishakhapatnam, Andhra Pradesh,India.

k.Shirley Wellfare institute of science Technology and Management(WISTM), Department of mechanical Engineering, Vishakhapatnam, Andhra Pradesh ,India.

Ch.Swetha working as a Assistant Professor in Department of mechanical Engineering at Vignan's institute of management and technology for women Vishakhapatnam, Andhra Pradesh ,India

(c) The Authors. Published by Blue Eyes Intelligence Engineering and Sciences Publication (BEIESP). This is an open access article under the CC BY-NC-ND license (http://creativecommons.org/licenses/by-nc-nd/4.0/) can be used in composite fibers to uplift the mechanical, thermal and electrical properties of the bulk product.The incorporated nano materials from improved fibers and resins are used in

new composites. The improvement in 3-D printing brought manufacturing in to names and small business. Which allows users to give life to an item an desktop which are created with the help of computer aided design. The reinforcements delivers the strength to composites with low material in minimum time and these can be designed and proto typed from the one among desktop. The worlds first carbon fiber 3-D printed was announced in 2014 by mark forged.

Classification of composites: The composite materials are classified in to various types. The classification is based on the geometry. The classification based on the geometry of reinforcement is convenient because the geometry of reinforcement is responsible for the mechanical properties and for high performance of the composites. The classification is listed on the table. The two classes of composites are: (1) Based on type of matrix materials. The composite materials are broadly classified in to 3 categories. First one is metal matrix composites (MMCS) Second one is Ceramic matrix composites(CMS) and the third one is polymer matrix composites(PMCS). Out of these three polymer matrix composite is widely used a it has simple manufacturing principle and it is low cost and has high strength. If the matrix material is polymer then the composite is polymer matrix composite.

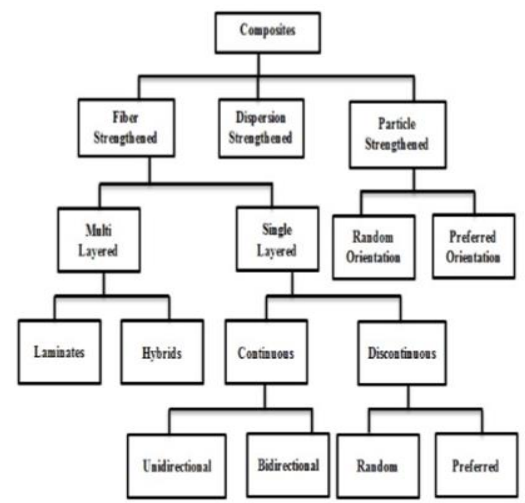

Table 1.1 Classification of Composites

A. Materials used as matrices in composites: The basic form of composite material is composition of two elements working together to produce various material properties. In general the composites consists of matrix and reinforcement of some kind which is added primarily to increase the strength and stiffness of the matrix. 


\section{Research on Mechanical \& Tribological Properties of Natural Fiber Composites}

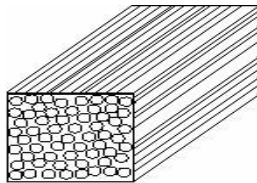

a

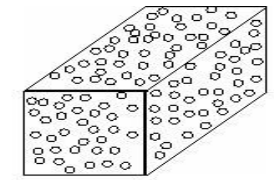

$b$

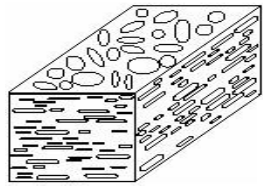

C
Fig;1.1(a) Continuous fiber (b) Particulate composites (c) Flake composites

Objective for selection: Applications of polymeric composite materials are used in automotive, marine, electrical, industrial, construction, household applications and sporting goods due to their light weight, high strength: Stiffness and corrosion resistance.
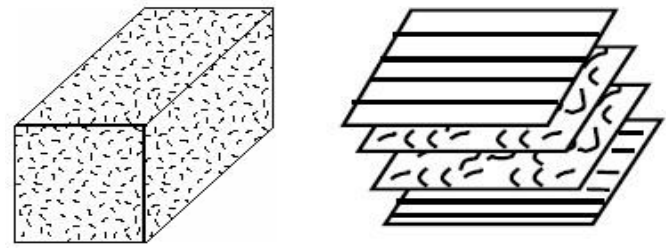

Fig ;1.2 (d)Random fiber composites (e) Laminate Composites

\section{METHODOLOGY}

The brief methodology of the entire project is shown in the form of flowchart shown in [figure 2.1]. It includes all the outlines of the project right from starting, which includes selection of materials to the end results. The in-depth review will be provided as we move further into the details of the entire process.

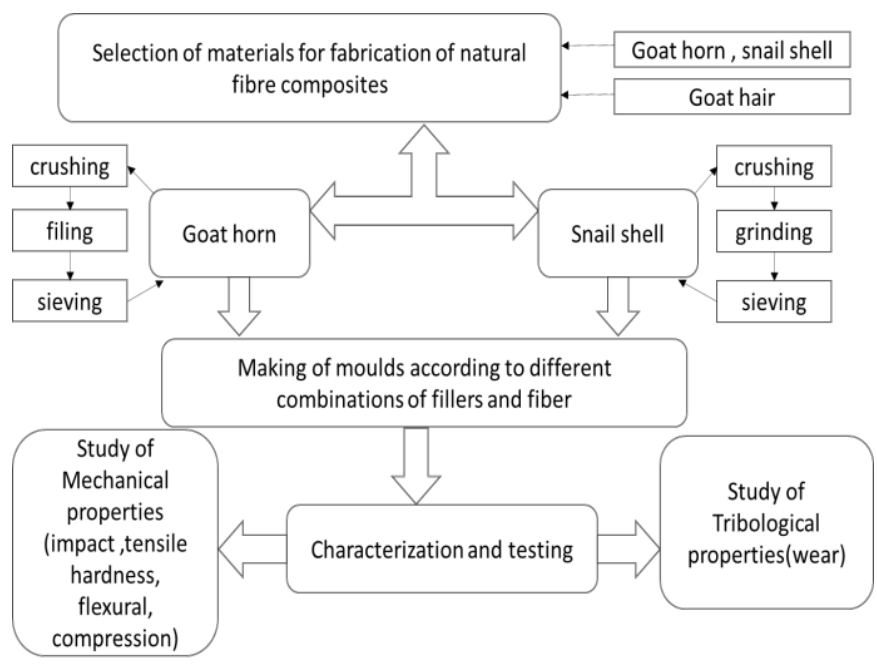

Figure 2.1: showing methodology adopted in making of composite

\section{III.REINFORCEMENT}

\section{A.Matrix Materials:}

Matrix is defined as the constituent which is present in greater quantity and continuous. The main purpose of matrix is hold or bind the fiber together and distributing the load evenly between fibers and also protects the fiber from mechanical \& environmental damages. Among the thermo set resins epoxy resin is the unique one due to different factors. The variant properties of epoxy are high corrosion and chemical resistance, outstanding adhesion to various substrate, good thermal and mechanical properties, good electrical insulating properties, low shrinkage upon cure. The ability to withstand under a variety of conditions make this matrix suitable material for the fiber reinforced composite materials. Several authors use epoxy resin for fabrication of polymer composites. The advantages mentioned above epoxy (LY556) chemically belongs to epoxies family. As is selected as matrix material for this project.

The epoxy resin (density $1.15 \mathrm{gm} / \mathrm{cc}$ ) and the corresponding hardener is HY-951.

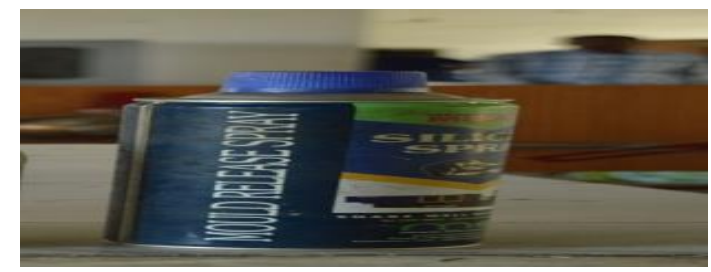

Figure :3.1 silicone spray

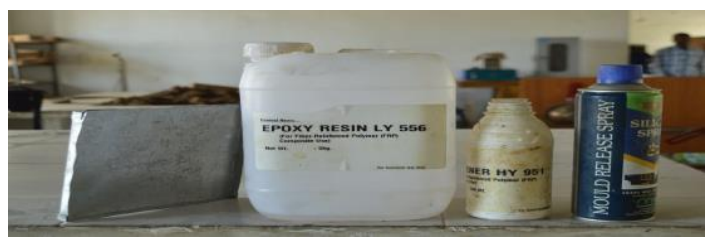

Figure: 3.2 ResinLY556 Hardener HY951

\section{B. Fiber Materials}

In composites, the strength of the material is enhanced by the discontinuous phase and is known as reinforcement. In reinforcing there are two phases one is fibrous, second one is non-fibrous. Fibers can with stand high amount of loads and it provides stiffness, structural properties, thermal stability and strength. Fibers are extracted from natural resources like living species, plants and they are named as natural fibers. Now a days composite materials plays a major role in all aspects because of their several advantages. The main advantage of natural fibers over remaining (synthetic) fibers are low density, renewability ,low cost and less health risk.

\section{Filler Materials}

When filler materials are added to the resin fillers can provide to improve properties including surface smoothness, water resistance, stiffness, temperature resistantance and dimensional stability. Calcium Carbonate occupies the largest place in the market sector while competing with remaining 21 fillers. It is mainly used in the plastic Industry's. Especially users precipitated calcium carbonate(pcc) which is obtained from natural materials. Thermosetting uses saw dust and wood floor as filler materials. Horns are found in different lengths, curvature and shapes. Horns are produced from structural proteins called Keratin which is strong and rigid. However, there is no significant research on use of horn powder as fillers in composites, we are trying to explore their use based on results.

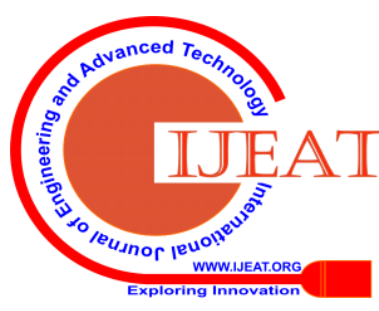


Snail shells are abundantly available on banks of oceans and have properties to be a good filler if adequate matrix structure and composition are known, which need to be studied.

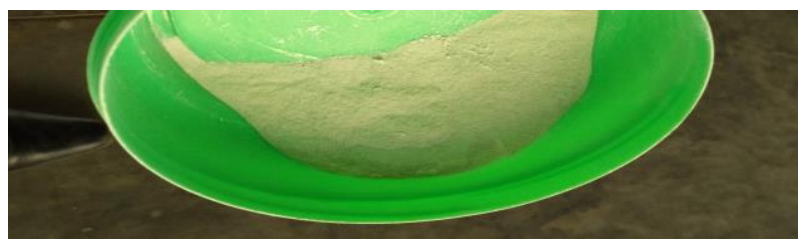

Figure 3.3 Grinded and sieved snail shell powder

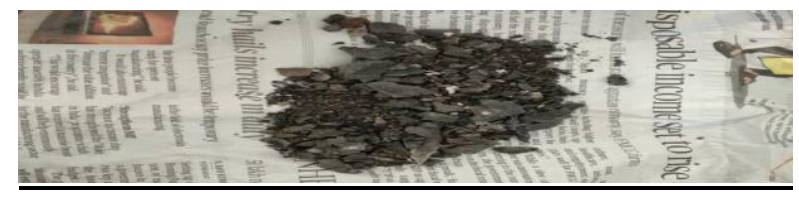

Figure 3.4(a) : Grounded horn

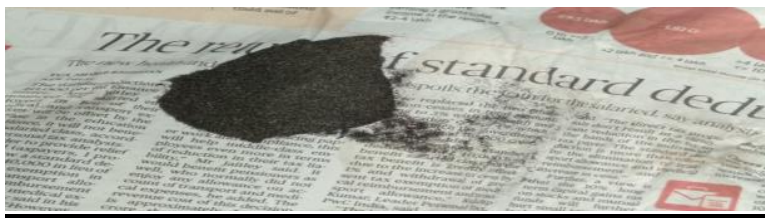

Figure 3.4(b): Fine Horn powder.

\section{PIN ON DISC DESIGN}

A stationary pin which is under an applied load is with a rotating disc. The pin can be of any shape in order to simulate a specific contact, but most oftenly spherical tips are used as

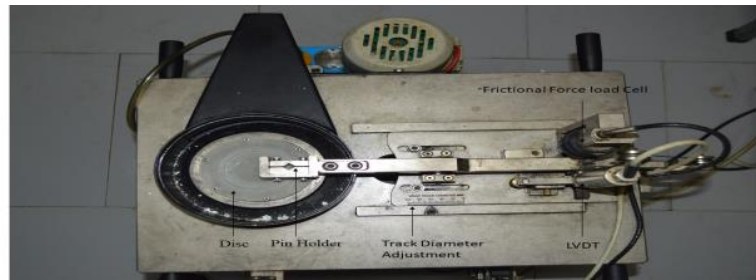

Figure: 4.0 POD apparatus

they can simplify the contact geometry The friction is calculated. If can be ratio of frictional force to loading force on the pin. For the friction test for low friction coatings such as diamond like carbon coatings on value train parts in internal combustion engine, the pic on disc test has proved more useful. The pin on disc is the flexible equipment designed to study frictional. stationary pin and a rotating disc. The normal load to the pin can be varied from 1 to $10 \mathrm{~kg}$ weight. The maximum mean dia of wear track is $74 \mathrm{~mm}$. The disc speed can be set between 95 to $1020 \mathrm{rpm}$.

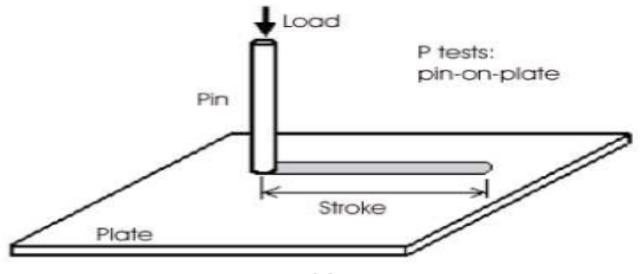

(a)

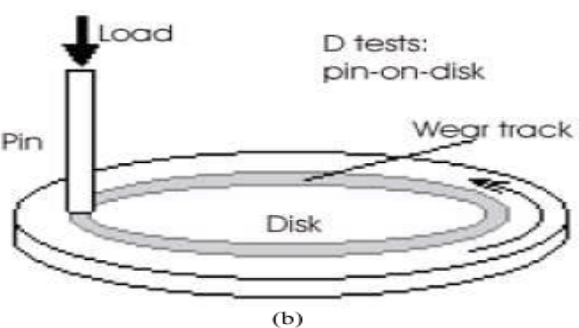

Figure 4.1Schematic of Tribotesting apparatus (a) Reciprocating and (b)Rotating

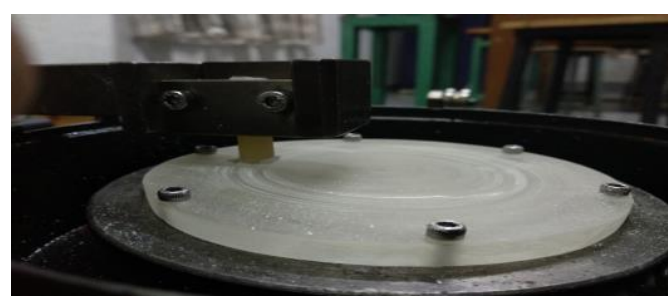

Figure 4.2 (b)Pin on Disc arrangement

\section{B. Experimental Set Up:}

The POD experimental set up consists of a machine, controller, weights and a connected PC. All these are connected via cables and the values of the controller are fed directly into the PC. [Figure 4.0] shows a view of the set up

\section{Design of Disc and Pin}

Disc is made up of AISI 1040 STEEL material. The dimensions of the discs are as follows:

\section{- Diameter: 100mm \\ - Thickness: $6 \mathrm{~mm}$}

The disc is made up according to the Standard dimensions to incorporate it into the space provided in the machine. The design of the disc is shown in [figure 5.0]. There are 6 holes arranged in a sequence as shown in the figure. These holes are drilled according to the said dimensions of the nut and bolt assembly to be used in clamping the disc.

\section{V.EXPERIMENTATION}

For experimentation process, we had already undergone through the different process for the better reinforcement of the materials. Hardener HY 951and EPOXY Resin LY 556 are chosen as they are abundantly available in the market. Raw Material used:

- Horn powder and Shell powder

-Goat Hair 


\section{Research on Mechanical \& Tribological Properties of Natural Fiber Composites}

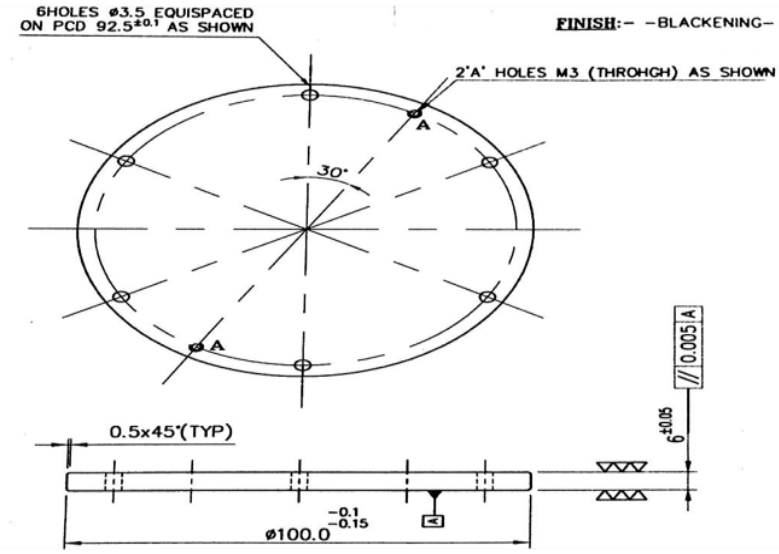

Figure 5.0: Sectional view of the plate

\section{A. Mould Preparation:}

GI Sheet boxes of size $200 * 200 * 15(\mathrm{~mm})$ were used for the moulding process. The moulded sheets are transformed into a square box such that the mixture of resin and hardener are poured in it. By Hand lay up technique the mould is carried to the mould cavity by proper care so that the mould cavity is filled thoroughly. To uniformly fill the cavity levelling was done with the help of rollers support.. Before that make sure that the moulding gel is to be used because, it will act as layer between the mould and box without giving any sticky nature to it. Because it leads to changes the properties of the composite material. Approximately 24 hours are taken for curing at room temperature once the cavity is done the mould is taken out of the mould cavity.

\section{B. Preparation of Composites}

The polymer matrix was prepared at room temperature. The ingredients like hardener, resin and grand nut shell ash are mixed continuously in a container. And then mixed turned into thick paste. The hardener and resin are taken in a proportion of $(1: 10)$ in a container and mixed well by the help of rod with proper care so that no air enters the solution.

silicone spray features

- Excellent anti stick $\backslash$ release property.

- Excellent anti -friction property resistance to moisture, humidity and corrosion.

- Imparts shine on plastic,metal, glass and painted wooden surfaces.

- Compatibility with most plastics and rubber.

- Non-staining,non-carbonizing and nontoxic in nature.

- Wide service temperature (-40c to +250c).

\section{Applications of Silicon Spray}

- Used as a release agent in injection moulding process of plastics components.

- Used as a release agent for reproduction of clean moulded articles.

- Provides the necessary lubrication to the moulds to prevent moulding defects.

- Used as a release agent for rubber moulded articles,resin casted products, wax based articles.

- Used as a release agent in metallurgical process.

\section{RESULT ANALYSIS}

Tensile test :The purpose of the universal testing machine (UTM) is to develop the stress strain diagram. Strength of the material which is axially loaded is determined by tensile test as shown in [figure 6.1]. By taking the samples the stress and strain can be calculated.

Stress= Applied force to Actual area, Strain=change in length to Actual length. The main objective of the test is to find the mechanical characteristics like ductility, toughness, elasticity and resilience.

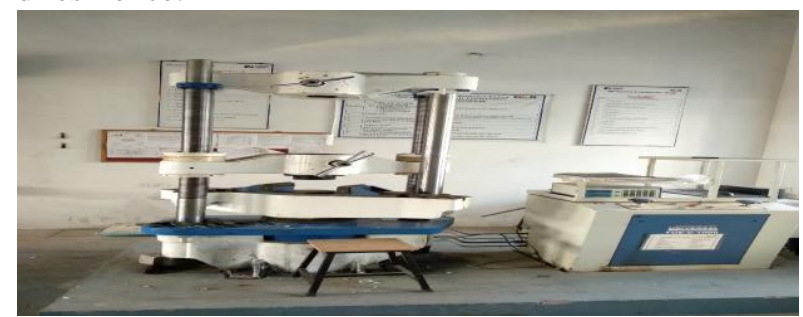

Figure:5.2 Universal testing Machine

\begin{tabular}{|l|l|l|l|l|l|l|l|}
\hline $\begin{array}{l}\text { Sample } \\
\text { No. }\end{array}$ & Name & $\begin{array}{l}\text { Epoxy } \\
\text { LY556 }\end{array}$ & $\begin{array}{l}\text { Hardener } \\
\text { HY951 }\end{array}$ & $\begin{array}{l}\text { Shell } \\
\text { Powder } \\
\text { (in gms) }\end{array}$ & $\begin{array}{l}\text { Hor } \\
\text { Powder } \\
\text { (in gms) }\end{array}$ & $\begin{array}{l}\text { Goat } \\
\text { Hair }\end{array}$ & Tests \\
\hline 1 & E+H+S & 352 & 35 & 12 & 0 & & completed \\
\hline 2 & E+H+S+HP & 352 & 35 & 6 & 6 & & completed \\
\hline 3 & E+H+S+GH & 349 & 34.9 & 8 & 0 & $\begin{array}{l}4 \text { gms } \\
(30 \%)\end{array}$ & completed \\
\hline 4 & E+H (Disc) & 400 & 40 & 0 & 0 & & completed \\
\hline 5 & E+H & 400 & 40 & 0 & 0 & & completed \\
\hline 6 & E+H+HP & 349 & 34.9 & 0 & 12 & & completed \\
\hline 7 & E+H+S+HP+GH & 352 & 35 & 4 & 4 & 4 gms & completed \\
& & & & & & & \\
\hline 8 & E+H+HP+GH & 349 & 34.9 & 0 & 8 & $4 \mathrm{gms}$ & completed \\
\hline
\end{tabular}

Table 6.1: Index of Specimens prepared and their compositions

\begin{tabular}{|c|c|c|c|}
\hline S.No & SPECIMEN NO. & $\begin{array}{l}\text { LOAD AT } \\
\text { BREAK(KN) }\end{array}$ & $\begin{array}{l}\text { MAXIMIMI LOAD } \\
\text { (KN) }\end{array}$ \\
\hline 1 & $\begin{array}{c}\mathrm{E}+\mathrm{H}+\mathrm{S} \\
(\mathrm{SPECIMEN} \mathrm{1)}\end{array}$ & 15 & 16 \\
\hline 2 & $\begin{array}{c}\mathrm{E}+\mathrm{H}+\mathrm{S}+\mathrm{HP} \\
(\mathrm{SPECTMEN} \mathrm{2)}\end{array}$ & 14.5 & 14.95 \\
\hline & $\begin{array}{c}\mathrm{E}+\mathrm{H}+\mathrm{S}+\mathrm{GH} \\
(\mathrm{SPECIMEN} \mathrm{3)}\end{array}$ & 14.8 & 15.82 \\
\hline & $\begin{array}{c}\text { E+H } \\
\text { (SPECTMEN 5) }\end{array}$ & 12 & 15.4 \\
\hline 5 & $\begin{array}{c}\text { E+H+HP } \\
\text { (SPECIMEN 6) }\end{array}$ & 14.8 & 15.92 \\
\hline 6 & $\begin{array}{l}\mathrm{E}+\mathrm{H}+\mathrm{S}+\mathrm{HP}+\mathrm{GH} \\
(\mathrm{SPECIMEN} 7)\end{array}$ & 15.2 & 15.5 \\
\hline 7 & $\begin{array}{l}\text { E+H+GH+HP } \\
\text { (SPECTMEN 8) }\end{array}$ & 14.82 & 15.23 \\
\hline
\end{tabular}

Figure:6.2 Tensile test 


\section{CONCLUSIONS AND DISCUSSIONS}

From this, compressive, impact and hardness tests are conducted on banana, jute hybrid composites. Data is analysed and compared. Whereas from the above results and discussions, it was proved that by using these composites some of the mechanical properties are enhanced (Tensile, Compressive, Impact) so these can be used in future for better mechanical properties it is proved that from all the above prepared composites, JBBJ composite with filler (specimen 3) shows the highest hardness value. BJJB composite filled with filler material shows the highest tensile strength (15.23). Composite prepared with filler(specimen3) shows the highest compressive strength $(52.9 \mathrm{KN})$. Composite prepared with JBBJ filled with filler shows the highest impact strength $\left(0.44 \mathrm{~J} / \mathrm{M}^{2}\right)$ on Izod.

Mechanical properties are increased with varying the composite of fibers and resins. Different tests like surface roughness test, wear test friction, are done to utilize the application of Banana jute hybrid composites. From the results, For the composite BJJB without filler we found the best wear and coefficient of friction at rotational speed 150 $\mathrm{rpm}$, at time240 sec, sliding distance $122.46 \mathrm{mts}$, at load 0.5 $\mathrm{kg}$ is 30 and 0.023 respectively. For the composite BJJB with filler we found the best wear and coefficient of friction at rotational speed $150 \mathrm{rpm}$, at time240 sec, sliding distance $122.46 \mathrm{mts}$, at load $0.5 \mathrm{~kg}$ is 14 and 0.036 respectively. For the composite JBBJ without filler we found the best wear and coefficient of friction at rotational speed $100 \mathrm{rpm}$, at time240 sec, sliding distance $69.08 \mathrm{mts}$, at load $1.5 \mathrm{~kg}$ is 20 and 0.021 respectively. For the composite JBBJ with filler we found the best wear and coefficient of friction at rotational speed 150 $\mathrm{rpm}$, at time120 sec, sliding distance $51.81 \mathrm{mts}$, at load $0.5 \mathrm{~kg}$ is 90 and 0.03 respectively. Fibers are easily produced and available in bulk even the preparation of these composites is a very easy process.

\section{REFERENCES}

1. Haigler, C. H. 1985, The Functions and Biogenesis of Native Cellulose, Cellulose Chemistry and Its Applications. T. P. Nevell and S. H. Zeronian. West Sussex, Ellis Horwood Limited

2. Bolvari A, Glenn S, Janssen R and Ellis C 1997 Wear and friction of aramid fiber and polytetrafluoroethylene filled composites Wear 203-204 697-702.

3. Rowell, R.M., Young, R.A., and Rowell, J.K., 1997, Chemical Composition of Fibers: Paper and Composites from Agro-based Resources, Lewis Publishers, CRC Press.

4. Srinivasan V S, Rajendra Boopathy S, Sangeetha D and Vijaya Ramnath B 2014 Evaluation of mechanical and thermal properties of banana-flax based natural fibre composite Mater. Des. 60 620-627

5. Ibrahim R A 2015 Tribological performance of polyester composites reinforced by agricultural wastes Tribol. Int. 90 463-466

6. Akil H M, Omar M F, Mazuki A A M, Safiee S, Ishak Z A M and Abu Bakar A 2011 Kenaf fiber reinforced composites: A review Mater. Des. 32 4107-4121.

7. Jeyanthi S and Janci Rani J 2012 Improving mechanical properties by KENAF natural long fiber reinforced composite for automotive structures J. Appl. Sci. Eng. 15 275-280

8. Rajasekaran T, Palanikumar K and Vinayagam B K 2011 Application of fuzzy logic for modeling surface roughness in turning CFRP composites using CBN tool Prod. Eng. 5 191-199.

9. Bolvari A, Glenn S, Janssen R and Ellis C 1997 Wear and friction of aramid fiber and polytetrafluoroethylene filled composites Wear 203-204 697-702

10. Gokul K, Prabhu T R and Rajasekaran T 2017 Processing and Evaluation of Mechanical Properties of Sugarcane Fiber Reinforced Natural Composites Trans. Indian Inst. Met. 70 2537-2546 (11) Wang Q hua, Zhang X rui and Pei X qiang 2010 Study on the friction and wear behavior of basalt fabric composites filled with graphite and nano-SiO2 Mater. Des. 31 1403-1409

11. Nirmal U, Yousif B F, Rilling D and Brevern P V. 2010 Effect of betelnut fibres treatment and contact conditions on adhesive wear and frictional performance of polyester composites Wear 268 1354-1370

12. Gokul K, Prabhu T R and Rajasekaran T 2017 Processing and Evaluation of Mechanical Properties of Sugarcane Fiber Reinforced Natural Composites Trans. Indian Inst. Met. 70 2537-2546.

13. P.K. Mallick., Fiber Reinforced composites, Third Edition.

\section{AUTHORS PROFILE}

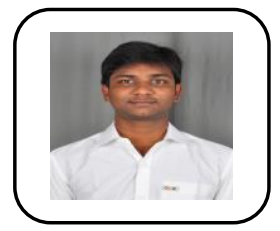

Shaik.Ahmad, working as a Assistant Professor in Department of mechanical Engineering at Wellfare institute of science Technology and Management(WISTM), ， Vishakhapatnam, Andhra Pradesh ,India

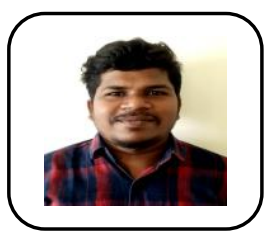

M.v.j.t.Arun, working as a Associate Professor in Department of mechanical Engineering at Wellfare institute of science Technology and Management(WISTM),Vishakhapatnam, Andhra Pradesh ,India

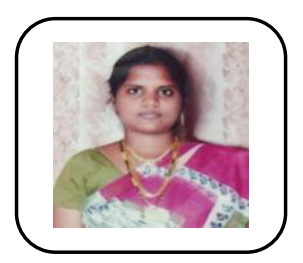

B.Vimala Kumari, working as a Associate Professor in Department of mechanical Engineering at Wellfare institute of science Technology and Management(WISTM), Vishakhapatnam, Andhra Pradesh ,India

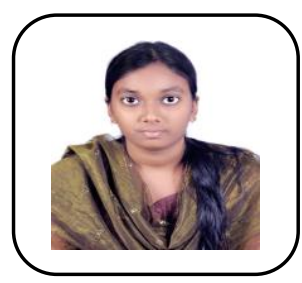

k. Shirley, working as a Assistant Professor in Department of mechanical Engineering at Wellfare institute of science Technology and Management (WISTM)Vishakhapatnam, Andhra Pradesh ,India

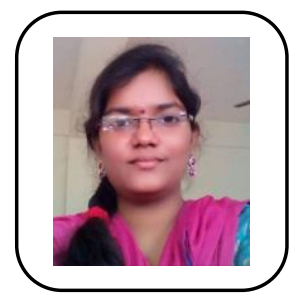

Ch. Swetha, working as a Assistant Professor in Department of mechanical Engineering at Vignan's institute of management and technology for women Vishakhapatnam, Andhra Pradesh ,India 